The 49th Annual Conference of the International Association of School Librarianship

The 24th International Forum on Research on School Librarianship

July 12 - 16, 2021

Jennifer Moore, Joe Sanchez, Alissa Tudor

University of North Texas, University of New York, University of North Texas

Jennifer.Moore@unt.edu, Jose.Sanchez2@.qc.cuny.edu, AlissaTudor@my.unt.edu

\title{
Weaving a Storytelling Tapestry Using Computational Thinking
}

\begin{abstract}
Computational thinking is a way of formulating a problem so that a computer can find a solution. It involves looking for patterns within multiple sets of data and using algorithmic thinking to find solutions. In this way, it becomes a critical literacy for future-ready youth. In this paper the authors share partial results from a National Forum on Computational Thinking funded by the Institute of Museum and Library Services, explaining computational thinking, exploring cross-cultural connections of the story sequence, and sharing how computational thinking can be used to create and analyze a story within the context of this story sequence.
\end{abstract}

Keywords: computational thinking; school libraries; storytelling

\section{Introduction}

Computational thinking (CT), within the context of computer science (CS), has traditionally been defined as formulating a problem so that a computer can find a solution (Wing, 2006). It involves looking for patterns within multiple sets of data and using algorithmic thinking to find solutions. In this way, it becomes a critical literacy for future-ready youth. In this paper the authors share partial results from their National Forum on Computational Thinking (funded by the Institute of Museum and Library Services), explaining computational thinking within the context of library and information science (LIS), exploring cross-cultural connections of the story sequence, and sharing how computational thinking can be used to create and analyze a story within the context of the story sequence.

\section{The Sequence of Stories}

In his 1949 book The Hero with a Thousand Faces, Joseph Campbell explained how dreams inspire the mythology of a culture by appealing to common universal truths central to humans. Campbell studied mythology from all over the world and discovered consistent characteristics, especially with the myth of the hero. He described the idea of the "monomyth" as "the standard 
path of the mythological adventure of the hero" (Campbell, 2008, p. 23). This monomyth spans cultures, both ancient and modern, to encompass a universal structure that is commonly found in myths, literature, television shows, movies, and video games. From the story of the Great Struggle of the Buddha to the American Indian tale of the Spider Woman, the journey of the hero has been replicated across cultures time and time again (Campbell, 2008).

Campbell's (2008) original Hero's Journey consisted of 17 stages divided into three parts: Departure, Initiation, and Return. In 1992, Christopher Vogler simplified the journey to 12 stages divided into what he calls the Ordinary World and the Special World. Vogler's 12 stages are detailed in Table 1 and are exemplified using Star Wars: A New Hope (Lucas, 1977).

\section{Table 1}

Vogler's 12 Stages of the Hero's Journey

\begin{tabular}{|c|c|c|}
\hline Stage: & Definition: & $\begin{array}{l}\text { Example: Star Wars A New } \\
\text { Hope }\end{array}$ \\
\hline The Ordinary World & Typical everyday life of the hero & $\begin{array}{l}\text { Luke Skywalker is living on } \\
\text { Tatooine with his aunt and uncle. }\end{array}$ \\
\hline The Call to Adventure & $\begin{array}{l}\text { The hero is called to go on an } \\
\text { adventure to confront a challenge or a } \\
\text { problem. }\end{array}$ & $\begin{array}{l}\text { R2D2 arrives with a mission to } \\
\text { find Obi Wan. }\end{array}$ \\
\hline Refusal of the Call & The hero expresses reluctance & Luke doesn't want to go. \\
\hline Meeting the Mentor & $\begin{array}{l}\text { A guide provides advice, knowledge, } \\
\text { or assistance }\end{array}$ & $\begin{array}{l}\text { Luke meets Obi Wan and learns } \\
\text { about the force. }\end{array}$ \\
\hline Crossing the Threshold & $\begin{array}{l}\text { The hero enters the Special World and } \\
\text { accepts the Call }\end{array}$ & Luke arrives at the cantina. \\
\hline Test, Allies, Enemies & $\begin{array}{l}\text { The hero is confronted with many } \\
\text { obstacles and challenges and meets } \\
\text { other characters who assist or hinder } \\
\text { their progress }\end{array}$ & $\begin{array}{l}\text { Luke encounters Darth Vader } \\
\text { and Stormtroopers on his } \\
\text { journey. }\end{array}$ \\
\hline Approach & $\begin{array}{l}\text { The hero enters the final test where the } \\
\text { object of the challenge is located }\end{array}$ & Luke arrives on the Death Star. \\
\hline Ordeal, Death, Rebirth & $\begin{array}{l}\text { The critical moment and climax in } \\
\text { which the hero faces the challenge }\end{array}$ & $\begin{array}{l}\text { Luke and Leia are trapped in the } \\
\text { trash compactor on the Death }\end{array}$ \\
\hline
\end{tabular}




\begin{tabular}{|l|l|l|}
\hline & & Star. \\
\hline Reward & The hero receives their prize & $\begin{array}{l}\text { Luke rescues Princess Leia and } \\
\text { gets the plans to the Death Star. }\end{array}$ \\
\hline The Road Back & $\begin{array}{l}\text { The hero travels back to the Ordinary } \\
\text { World }\end{array}$ & $\begin{array}{l}\text { Luke and Leia try to escape the } \\
\text { Death Star. }\end{array}$ \\
\hline Resurrection & $\begin{array}{l}\text { The hero is tested once more before } \\
\text { returning to the Ordinary World and } \\
\text { proves they have changed as a result of } \\
\text { their journey }\end{array}$ & $\begin{array}{l}\text { Luke is almost killed but he } \\
\text { survives. }\end{array}$ \\
\hline Return with the Elixir & $\begin{array}{l}\text { The hero returns to the Ordinary } \\
\text { World armed with a new special } \\
\text { knowledge }\end{array}$ & $\begin{array}{l}\text { Luke defeats Darth Vadar and is } \\
\text { now a Jedi, a rebel, and he has a } \\
\text { purpose in life. }\end{array}$ \\
\hline
\end{tabular}

Because of the natural pattern-like structure, the Hero's Journey can be used as a formula for storytelling. Vogler (2007) echoes this idea stating that the "Hero's Journey is a skeletal framework that should be fleshed out with the details" (p. 21) and that it is "infinitely flexible" (p. 22). The individual stages of the Hero's Journey can be sequenced and organized into a larger narrative to form a cohesive plot.

Dan Harmon, creator of the television shows Community and Rick \& Morty, further simplified the structure into 8 stages and illustrated the stages using a circle, with order in the top half and chaos in the bottom half (Figure 1). The stages include

- You: the protagonist with whom the reader/viewer can identify is established.

- Need: a problem or need presents itself.

- Go: to solve the problem or meet the need, the protagonist must cross a threshold. This is where the story changes direction from order to chaos.

- Search: the protagonist experiences trials while searching for the resolution.

- Find: the protagonist finds a resolution.

- Take: the protagonist must pay a price for finding the resolution.

- Return: the protagonist returns to the world where they began. This is where the story changes from chaos to order.

- Changed: the protagonist is now a changed person because of the experience (Studiobinder, 2020). 


\section{Figure 1}

\section{Dan Harmon's Story Circle}

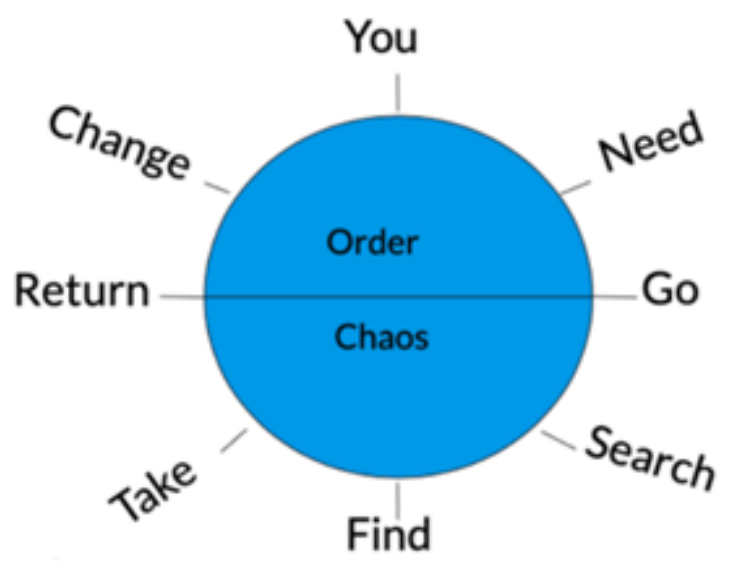

\section{Computational Thinking}

\section{What is Computational Thinking?}

Definitions for computational thinking (CT) vary based on the defining entity. Historically CT has been associated with computer science (CS) and has been identified as a systematic problem-solving process involving the formulation of problems in such a way for a computer to understand (Wing, 2006). Within the process are four primary concepts:

- Decomposition: Breaking down data, processes, or problems into smaller, manageable parts

- Pattern Recognition: Observing patterns, trends, and regularities in data

- Algorithm Design: Developing the step-by-step instructions for solving this and similar problems

- Abstraction: Identifying the general principles that generate these patterns by focusing on the important information only, ignoring irrelevant details (Google for Education, n.d.)

The BBC (2021) provides an illustrated model of CT concepts, as seen in Figure 2. 


\section{Figure 2}

\section{Computational Thinking Illustrated}

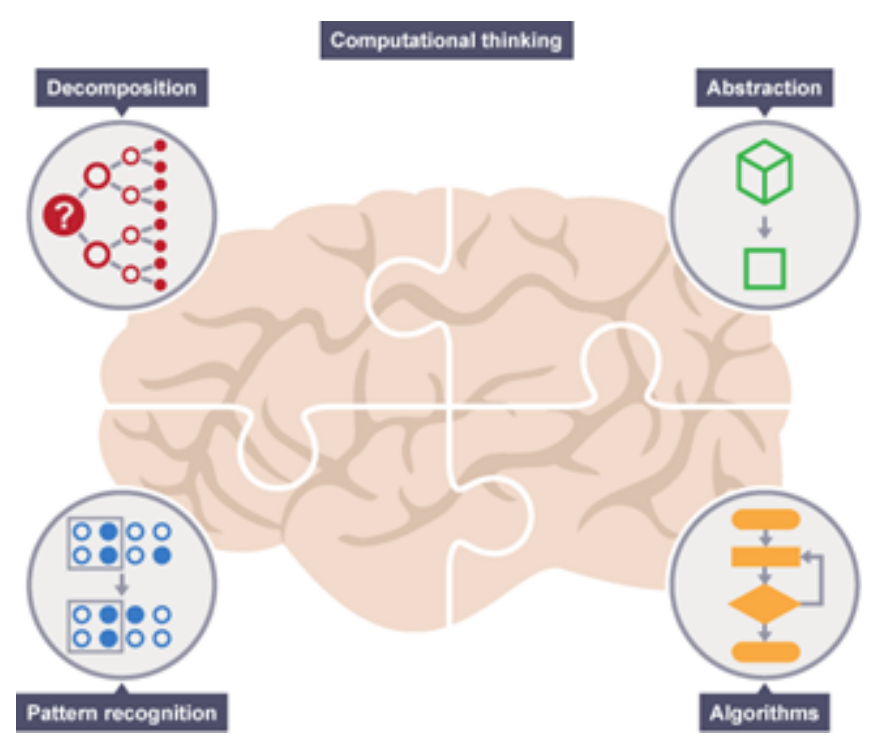

There are, of course, variations in the process depending on the defining entity, but for the sake of simplicity, this project focuses on this variation. Engaging in the process of computational thinking does not require the problem solver to work through all four concepts in order or even all four concepts at all. Sometimes the problem solver may only use decomposition, pattern recognition, and algorithm design, for example. Additionally, it is possible the problem solver works through certain concepts unknowingly.

To illustrate CT in general, think about a pizza recipe: there is one recipe for a cheese pizza, one recipe for a meat pizza, and one recipe for a vegetable pizza. For the sake of simplicity, only one type of crust will be imagined. Publishing three separate recipes requires more space and resources, either on paper or online. To reduce the need for the additional space and resources required by three separate recipes, one would provide a recipe for a basic cheese pizza, with the crust, sauce, and cheese ingredients and quantities. After the basic recipe, a few lines would be included for variations, specifying the ingredients and quantities for a meat pizza and then a few lines for the ingredients and quantities for a vegetable pizza.

\section{Computational Thinking in Computer Science and Library and Information Science}


CT is not, however, a discipline, nor is it limited to computer science (CS). CT and computer science are not interchangeable terms, but they are related because CT is a foundational skill applicable to computer science. CT is applicable to other facets in life, too. In education, CT prepares students to master K-12 STEM (science, technology, engineering, math) standards (Yadav, Hong, and Stephenson, 2016). The current iteration of International Society for Technology in Education (ISTE) Standards for Students (2019a) and International Society for Technology in Education (ISTE) Standards for Educators (2019b) identifies CT as one of the six major standards students should master during their K-12 experience, positing "students develop and employ strategies for understanding and solving problems in ways that leverage the power of technological methods to develop and test solutions." Teaching students CT guarantees youth have skills essential to future employment and civic participation, as $\mathrm{CT}$ includes strategies and skills from problem solving, critical thinking, debugging, creativity, and collaboration. These skills are already in demand in the workforce and are predicted to be necessary for the workforce of the future.

Libraries, both public and school, are ideal locations for teaching CT for multiple reasons. School libraries are often the largest inclusive classroom, and the school librarian has the opportunity to interact with every student on campus. Library programs offer innovative and customized informal and formal learning spaces for all, thus improving access to skill development and resources for all learners. When collaborating with classroom teachers, librarians have the opportunity to integrate $\mathrm{CT}$ into multiple curricular areas, thus facilitating in the development of critical thinking skills and problem-solving skills. Librarians also have the opportunity to prepare students for their educational careers, their professional careers, and their everyday life issues.

Currently, however, there is a disconnect between CT within the context of CS and LIS. CT skills are applicable to CS, and CT in CS focuses on skills required for computing. CT skills also transfer to education, college readiness, career readiness, and everyday life issues. The LIS community as a whole acknowledges the necessity for youth to be proficient in STEM, but LIS also focuses on people holistically. Individuals and communities need problem solving skills applicable to multiple arenas. Youth need access to formal and informal learning opportunities allowing them to develop CT skills in a wider context (Sykora, 2014; Smith, 2016; Braun \& Visser, 2017). Public and school librarians have provided resources and programming to encourage lifelong, formal, and informal learning, thus making libraries an ideal space to facilitate CT skill development. 


\section{Weaving Together Computational Thinking and Storytelling}

\section{Inspiration: First National Forum}

With funding provided by the Institute of Museum and Library Services (RE-12-19-0094-19) and inspiration provided by the American Library Association and Google funded Libraries Ready to Code initiative's findings (Martin, 2017), the authors hosted two national forums recontextualizing CT outside of the CS domain by creating CT resources highlighting the connection between technology and people rather than efficient computation. In Forum 1, 12 faculty members from LIS, Learning Sciences, and Educational Technology collaboratively developed a framework for three modules grounding CT within the LIS domain, to emphasize the connection between people and technology, especially underrepresented groups, rather than efficient computing. One module focused on using computational thinking to teach storytelling.

In Forum 2, 18 pre-service and practicing school and youth services public librarians tested the modules to determine what revisions were needed so these modules' activities could be integrated into library lessons and programming for youth. Participants attended a virtual orientation where they learned about CT, were divided into three groups (one group for each module), and received a short list of articles to read. Each module's group met once virtually, for three hours, where they completed tasks associated with the modules and provided feedback. For the storytelling module, small groups created a cohesive story using disconnected pieces, or blocks, similar to a block coding experience.

\section{CT and storytelling Sequencing}

CT concepts can be found in the process of storytelling.

- Problem statement: Creating a cohesive story using disconnected pieces/blocks

- Decomposition: Break the story into manageable pieces. Examine Act 1 (you, need, go), Act 2 (search, find, take), and Act 3 (return and change)

- Pattern recognition: The patterns are identified within the story circle.

- Algorithm design: Following the path of the story circle and adding conditional statements and loops. 
- Abstraction: Ability to create your own story or evaluate existing works using a model. Abstraction can also be seen in the story outline the participants created; they created an overview of their narratives, ignoring most of the details.

\section{Module 1 Curriculum}

\section{Module Objectives}

The focus of Module 1 was on creating a cohesive story using disconnected pieces. The objectives participants were to master by the completion of the module include:

- Create a story that demonstrates the use of sequencing, conditional logic, and pattern recognition (key concepts under algorithmic thinking).

- Articulate the CT concepts in their own words.

- Identify the concepts of sequencing, conditional logic, and pattern recognition in another person's story.

- Manipulate variables.

- Articulate their story paths.

- Reflect on the process (going through the debugging process).

\section{Module Activities}

After reviewing computational thinking and the module objectives, participants were tasked with creating a cohesive story outline using story building blocks the authors provided. Because the forum was held online, the authors selected Google's Jamboard as the tool on which participants worked. Participants were divided into groups of three. Each group was given a template with story building blocks (Figure 3 ) that they used to virtually manipulate and create a story, using Harmon's story circle as a guide (Studiobinder, 2020). The participants also had to include a conditional statement and a loop in their story, mimicking the coding experience. Each group shared their story with the other group, and a debugging process followed. At the conclusion of the activity, the objectives were reviewed, and participants had mastered each objective. 
Figure 3

Story Building Blocks

\begin{tabular}{|c|c|c|c|}
\hline Protagonist & Setting & Challenge & Ending \\
\hline Robot & Airplane & $\begin{array}{l}\text { Finding a } \\
\text { good } \\
\text { parking } \\
\text { spot }\end{array}$ & $\begin{array}{l}\text { Returned } \\
\text { the panda } \\
\text { to its } \\
\text { home }\end{array}$ \\
\hline Nurse & Desert & $\begin{array}{l}\text { Spraining } \\
\text { your ankle }\end{array}$ & $\begin{array}{c}\text { Lived } \\
\text { happily } \\
\text { ever after }\end{array}$ \\
\hline Alligator & Mall & $\begin{array}{c}\text { Deflvering } \\
\text { milk } \\
\text { during a } \\
\text { heat wave }\end{array}$ & $\begin{array}{l}\text { Slept well } \\
\text { for the } \\
\text { first night } \\
\text { in years }\end{array}$ \\
\hline Farmer & Circus & $\begin{array}{l}\text { Missing } \\
\text { your } \\
\text { alrpplane } \\
\text { flight }\end{array}$ & $\begin{array}{l}\text { Won the } \\
\text { blueberry } \\
\text { ple eating } \\
\text { contest }\end{array}$ \\
\hline $\begin{array}{l}\text { Wild } \\
\text { card }\end{array}$ & $\begin{array}{l}\text { Wild } \\
\text { card }\end{array}$ & $\begin{array}{l}\text { Wild } \\
\text { card }\end{array}$ & $\begin{array}{l}\text { Wild } \\
\text { card }\end{array}$ \\
\hline
\end{tabular}

\section{Conclusion}

Computational thinking is traditionally associated with computer science and has only recently begun to be explored in library and information science. As part of a national forum grant funded by the Institute of Museum and Library Services, authors worked with 12 faculty members from LIS, Learning Sciences, and Educational Technology to develop a framework for three modules grounding CT within the LIS domain. The authors then further developed the modules, and 18 pre-service and practicing school and youth services public librarians tested each module. Although computational thinking and storytelling are two seemingly unrelated concepts, the authors and national forum participants wove the threads together, creating rather unique and interesting storytelling tapestries. 


\section{References}

BBC. (2021). Introduction to computational thinking. Bitesize. Retrieved from https://www.bbc.co.uk/bitesize/guides/zp92mp3/revision/1

Braun, L. \& Visser, M. (2017). Ready to code: Connecting youth to CS opportunity through libraries. $\quad$ Retrieved from http://www.ala.org/advocacy/sites/ala.org.advocacy/files/content/pp/Ready To Code Report FI NAL.pdf

Campbell, J. (2008). The hero with a thousand faces (3rd ed.). New World Library.

Google for Education. (n.d.). CT overview. Retrieved from https://edu.google.com/resources/programs/exploring-computational-thinking/\#!ct-overview

International Society for Technology in Education. (2019a). ISTE standards for students.

Retrieved from https://www.iste.org/standards/for-students

International Society for Technology in Education. (2019b). ISTE standards for educators. Retrieved from https://www.iste.org/standards/for-educators

Lucas, G. (Director). (1977). Star wars: Episode IV [Film]. USA: 20th Century Fox Home Entertainment.

Martin, C. (2017). Libraries Ready to Code final Phase II evaluation. Unpublished evaluation report, American Library Association, Public Policy and Advocacy Unit, Washington, District of Columbia, United States.

Smith, M. (2016). Computer science for all. Retrieved from https://obamawhitehouse.archives.gov/blog/2016/01/30/computer-science-all 
Studiobinder. (2020, August 23). How the Dan Harmon story circle can make your story better. Retrieved from https://www.studiobinder.com/blog/dan-harmon-story-circle/

Sykora, C. (2014). Computational thinking for all. Retrieved from https://www.iste.org/explore/Solutions/Computational-thinking-for-all

Vogler, C. (2007). The writer's journey: Mythic structure for writers (3rd ed.).

Michael Wiese Productions.

Wing, J. M. (2006). Computational thinking. Communications of the ACM 49(3), 33-35.

Yadav, A., Hong, H., and Stephenson, C. (2016). Computational thinking for all: Pedagogical approaches to embedding 21 st century problem solving in K-12 classrooms. TechTrends, 60(6), $565-568$.

\section{Biographies}

Jennifer Moore is a former school librarian and current Associate Professor in the Information Science Department at the University of North Texas, Denton, Texas, USA.

Joe Sanchez is an Associate Professor in the Graduate School of Library and Information Studies at Queens College in the City University of New York.

Alissa Tudor is a youth services librarian and former teacher. She is currently pursuing her $\mathrm{PhD}$ in Information Science at the University of North Texas.

\section{Acknowledgement}

The authors would like to thank the Institute of Museum and Library Services (IMLS) for their generous support of the national forums. 